\title{
Study of Cluster based Routing Protocols in Wireless Sensor Networks
}

\author{
Kalyan Krishna Awasthi \\ Department of Electronics and \\ Communication Engineering \\ Babu Banarasi Das National \\ Institute of Technology \& \\ Management \\ Lucknow, India
}

\author{
Arun Kumar Singh \\ Department of Electronics and \\ Communication Engineering \\ Goel Institute of Technology \& \\ Management \\ Lucknow, India
}

\author{
Shailendra Tahilyani \\ Department of Electronics and \\ Communication Engineering \\ Babu Banarasi Das National \\ Institute of Technology \& \\ Management \\ Lucknow, India
}

\begin{abstract}
Wireless sensor networks have found immense application after the advancement of wireless technology. A wireless sensor network is a combination of large number of sensing devices called sensor nodes. The communication between these sensor nodes is governed by a number of routing protocols which follow varying strategies. These protocols are extensively responsible for the performance of any wireless sensor network. This paper presents an extensive survey and study of various routing protocols based on different administrative strategies.
\end{abstract}

\section{Keywords}

WSN, Sensor node, Routing Protocols

\section{INTRODUCTION}

Wireless Sensor network has emerged as a premier research topic because of its potentially large application field. A wireless sensor network has a number of small nodes which independently have very low functionality but collectively find a huge application area. Under normal deployment and functionality once a sensor network is laid down it is left to function as an independent unit without being attended on a regular basis. The structure of a wireless node is shown in Figure 1

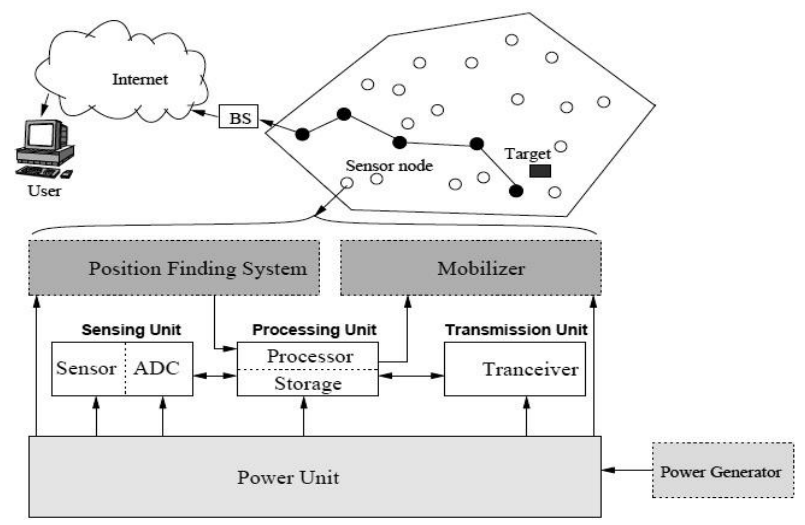

Fig.1. Sensor Node Architecture (source: [1])

The main part of a sensor node is the power unit which is basically a battery or set of batteries. The power once depleted is difficult to be regenerated again so power conservation is an important constraint in any sensor device. All the processing functions are performed by the processing unit which is basically a microcontroller provided with a memory unit. This memory unit stores the data on temporal basis. A sensor node senses the data through its sensing unit. Along with a sensing unit every node is endowed with a transmission unit which ensures the transmission and reception of data as and when required.

The organization of the remaining paper is as follows-Section II throws some light on the already existing routing protocols, Section III discusses the protocols bifurcation on clustering strategy, Section IV discusses the various existing issues with theses protocols and finally Section V concludes the paper.

\section{DESIGN STRATEGIES IN WSN}

The method of finding an appropriate path between the source and the destination is called as routing. In a wireless sensor network the type and function of every network has a very wide variation so the routing problem becomes quite a challenge for the network design. Routing has to be in such a manner that the path followed for data communication should be minimum with least dissipation of energy. Routing protocols make sure that the energy requirements are properly satisfied $[2,3]$. The main objective of any routing protocol is to make sure that the network remains connected for most of the time and the network lifetime is extended to a considerable extent. To abide by the design constraints [4], the following parameters must be kept in mind:

1. A very important parameter is the location where the nodes are deployed. This parameter to a large extent is dependent on the application. The nodes can either be deployed in a random manner or systematic manner. In random deployment the nodes are placed manually and the path through which the data is to be transmitted is pre-decided. This enables to efficiently cover the desired area but does not give good results when the sustaining environment for the nodes is adverse [5]. In another approach the nodes are distributed in a random manner. This distribution is effective when we have to deal with the event based decision making. [6, 7].

2. The process of sensing, processing and transmitting/receiving data involves a considerable amount of energy. Every node in a wireless sensor network has a fixed amount of energy. This energy is utilized when the data is processed in any manner [8]. Smart utilization of this energy is a major design constraint in every network. Energy optimization should not compromise the accuracy of the network. There has to be a proper balance between the accuracy and energy optimization $[9,10]$

3. The nodes that are usually deployed in any wireless sensor network are homogenous nodes and 
heterogeneous nodes. In homogenous distribution of nodes the characteristics and nature of all the attributing nodes is almost of same behavior whereas in heterogeneous distribution the properties of each and every node may vary [2]. In certain specific applications the nodes may be movable [11].

4. Another important design parameter is the area which is to be covered by a particular wireless sensor network [8].

5. There may be a case where a very large number of nodes are present in a network. The wireless sensor network should ably cope with a very large number of nodes [2, 8]. It is not required that each node should have the knowledge of entire node distribution of the network.

6. In the applications which involve real time data handling Quality of Service holds importance [12] and thus can be considered a design issue.

The routing of the input data is done at the network layer. The information from the source node might not necessarily reach the sink directly. There may be a multi path hopping of the data from source to destination node. In such hopping the intermediate nodes play a very vital role as they sense the data and process it as per the required destination. The establishment of the routing path for data processing thus holds a lot of importance. These routing protocols can establish these routing paths based on five different approaches- the method in which the path is set up, the distribution of the nodes in the network structure, the manner in which a particular protocol performs its function, the way in which the communication begins and the procedure followed by a protocol in selecting the next node where the preceding data is to be sent.

The taxonomy of the routing protocols is as follows:

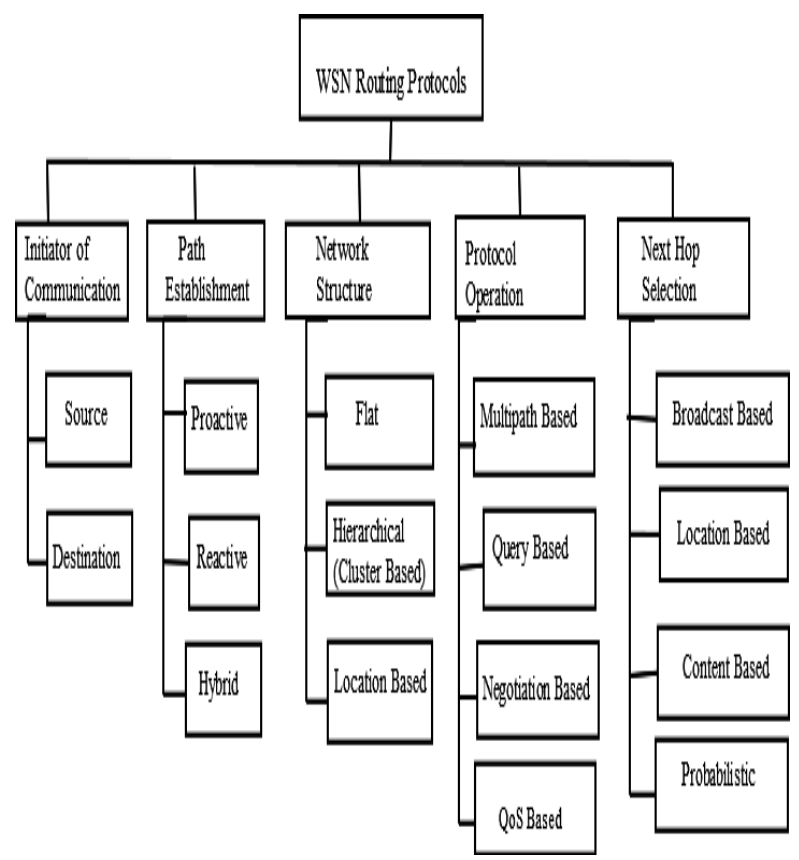

Fig.2. Taxonomy of Routing Protocols in WSN (source [1])

The network protocols either follow a flat strategy where every node performs the same function or a hierarchal cluster based strategy where the functions are strategically distributed at each level.

\section{CLUSTER BASED ROUTING PROTOCOLS}

The energy of all the constituent nodes in a wireless sensor network is different. A smart clustering based approach selects the nodes based on their residual energy content. If the nodes having sufficiently high energy are selected for the processing and transmitting of data and the nodes with considerably less energy are utilized for sensing data then the energy can efficiently be managed. The cluster based protocol stack follows the same approach $[13,14]$. The taxonomy is shown in Figure 3.

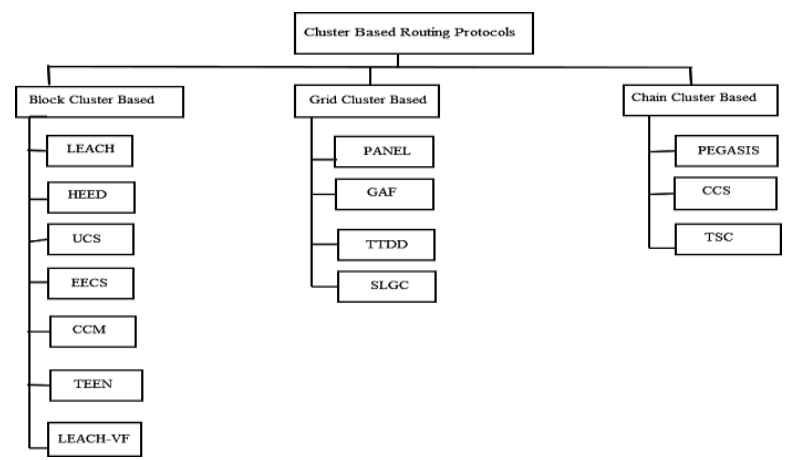

Fig.3. Taxonomy of cluster based Routing Protocols in WSN (source [1])

The existing cluster based routing protocols were studied and the comparative study of the various cluster based routing protocols $[1,15,16,17,18,19,20,21,22,23,24,25,26,27$, $28]$ is summarized in Table 1.

Table 1 Comparative Study of Cluster Based Protocols

\begin{tabular}{|c|c|c|c|c|}
\hline $\begin{array}{c}\text { Protocol } \\
\text { Name }\end{array}$ & $\begin{array}{c}\text { Efficiency } \\
\text { based on } \\
\text { Energy }\end{array}$ & $\begin{array}{c}\text { Time } \\
\text { taken in } \\
\text { packet } \\
\text { delivery }\end{array}$ & $\begin{array}{c}\text { Stability } \\
\text { of } \\
\text { Cluster }\end{array}$ & $\begin{array}{c}\text { Complexity } \\
\text { of } \\
\text { Algorithm }\end{array}$ \\
\hline LEACH & Very Low & $\begin{array}{c}\text { Very } \\
\text { Fast }\end{array}$ & Medium & Low \\
\hline HEED & Medium & Medium & High & Medium \\
\hline UCS & Very Low & Fast & High & Medium \\
\hline EECS & Medium & Fast & High & Very High \\
\hline CCM & Very Low & Fast & High & Medium \\
\hline $\begin{array}{c}\text { LEACH } \\
\text {-VF }\end{array}$ & Medium & Fast & High & Medium \\
\hline TEEN & Very high & Fast & High & High \\
\hline GAF & Medium & $\begin{array}{c}\text { Very } \\
\text { Fast }\end{array}$ & Medium & Medium \\
\hline PANEL & Medium & Medium & Low & High \\
\hline TTDD & Very Low & $\begin{array}{c}\text { Very } \\
\text { Slow }\end{array}$ & $\begin{array}{c}\text { Very } \\
\text { High }\end{array}$ & Low \\
\hline SLGC & Medium & $\begin{array}{c}\text { Very } \\
\text { Fast }\end{array}$ & Medium & Medium \\
\hline $\begin{array}{c}\text { PEGASI } \\
\text { S }\end{array}$ & Low & $\begin{array}{c}\text { Very } \\
\text { Slow }\end{array}$ & Low & High \\
\hline CCS & Low & Slow & Low & Medium \\
\hline TSC & Medium & Medium & Medium & Medium \\
\hline
\end{tabular}

\section{EXISTING ISSUES WITH CLUSTER BASED ROUTING PROTOCOLS}

Although a lot of work is being done in improving the efficiency of cluster based routing protocols but still there are certain pertinent issues that need to be dealt with proper concern. These issues are: 
1. The process of selecting a node as a cluster head is very important. This selection must properly be done considering the remaining energy of every node. There has to be a threshold energy level below which the network must readily hop from node to node.

2. Few nodes in the network remain attended when the deployment is over a wide area. The governing area must be considerable increased.

3. Network topology can change depending upon the terrestrial area where a particular network is functioning. More efficient clustering mechanisms need to be followed to improve network efficiency.

4. The sensor nodes should be self sufficient to handle minor faults.

5. Network needs to be designed with minimum number of possible nodes without compromising the accuracy and security.

\section{CONCLUSION}

Wireless Sensor Networks are finding a huge application in almost every field. This paper has surveyed the research work already done in this field. The paper has addressed various existing routing protocols along with their classification. A comparative study of various strategic cluster based routing protocols can serve a useful tool for various research scholars who are interested in modifying and optimizing the various routing algorithms used in wireless sensor networks. In future protocols may be proposed that identify the dead nodes before they actually die and improve the efficiency by hopping.

\section{REFERENCES}

[1] S.P. Singh, S.C. Sharma, "A survey on cluster based routing protocols in wireless sensor networks", Procedia Computer Science, Vol. 45. 2015. Pp. 687-695

[2] Al-Karaki, J.N., and A.E. Kamal, "Routing techniques in wireless sensor networks: a survey", IEEE Wireless Communication 11:6-28, 2004

[3] B. Krishnamachari, D. Estrin, S. Wicker, " Modelling data centric routing in wireless sensor networks", in Proceedings of IEEE IFOCOM, New York, NY, June 2002

[4] K. Akaya, M. Younis, "A survey on routing protocols for wireless sensor networks", Ad Hoc Networks, Vol. 3, 2005, pp. 325-349

[5] W.B. Heinzelman, A.P. Chandrakasan, H. Balakrishnanaa, "Application specific protocol architecture for wireless micro sensor networks", IEEE Transactions on Wireless Networking, 2002

[6] Mauri, K., Hannikainen, T., “ A Survey of application distribution in wireless sensor networks", EURASIP Journal on Wireless Communications and Networking, vol. 2005: pp.774-788,2005

[7] P. Kumar, M.P. Singh, and U.S. Triar, “ A Review of routing protocols in wireless sensor networks", International journal of Engineering Research and Technology (IJERT), vol. 1 no.4, pp. 1-14,2012

[8] Haneef, M., D. Zhongliang, “ Design challenges and comparative analysis of cluster based routing protocols used in wireless sensor networks for improving network lifetime”, Adv. Inform. Service Sci. 4:450-459, 2012
[9] Akyildiz, I.F., Varun, M.C., "Wireless Sensor Networks", John Wiley and Sons, 2010

[10] Cordiero, C.M., Agarwal, D.P., "Wireless Sensor Networks: Theory and Applications", World Scientific, Singapore, 2011.

[11] Ye, F., Luo, H., Cheng, J., Lu, S., Zhang, L., "A Two tier data dissemination model for large scale wireless sensor networks", in Proceedings of ACM/IEEE Mobicom, 2002.

[12] M. Hammoudeh, R. Newman, 'Adaptive routing wireless sensor networks: QoS optimization for enhanced application performance", Informat. Fusion 9(2013),http://dx.doi.org/10.1016/j.inffus.2013.02.005

[13] Ameer Ahmad Abbasi, Mohammad Younis, " A survey on clustering algorithms for wireless sensor networks", Computer Communication 30 (2007) 2826-2841

[14] X. Liu, " A Survey on clustering routing protocols in wireless sensor networks", Sensors, vol. 12, pp. 11113 11153,2012

[15] Heizelman, W. R., Chandrakasan, A., Balakrishnana, H., "Energy efficient communication protocol for wireless micro sensor networks", in Proceedings of Hawaii International Conference on System Sciences, 2000.

[16] O. Younis, S. Fahmy, "HEED: Ahybrid energy-efficient, distributed clustering approach for Ad Hoc sensor networks", IEEE Transactins on Mobile Computing 3(4) (2004) 366-379

[17] S. Soro, W.B. Heinzelman, " Prolonging the lifetime of wireless sensor networks via unequal clustering", in Proceedings of $19^{\text {th }}$ IEEE International Parallel and Distributed Processing Symposium, 2005

[18] M. Ye C. Li, G. Chen, and J. Wu, " EECS: An energy efficient clustering scheme in wireless sensor networks", in Proceedings of $24^{\text {th }}$ IEEE International performance, Computing and Communications Conference, pp. 535540,2005

[19] F. Tang, I. You, S. Guo, M. Guo, and Y. Ma, “ Achanin cluster based routing algorithm for wireless sensor networks", Journal of Intelligent Manufacturing, vol. 23, no. 4 , pp. $1305-1313,2010$

[20] M. B. Yassein, A. Al-Zou , Y. Khamayseh, and W. Mardini, "Improvement on LEACH Protocol of Wireless Sensor Network (VLEACH)", International Journal of Digital Content: Technology and its Applications, vol. 3 , no. 2, pp. 132-136, 2009

[21] A. Manjeshwar and D. P. Agarwal, “ TEEN: A Routing protocol for enhanced efficiency in wireless sensor networks" in Proceedings of $15^{\text {th }}$ International Parallel and distributed processing symposium, pp. 2009-2015

[22] L. Buttyan and P. Schaffer, " PANEL: Position-based aggregator node election in wireless sensor network," in proceedings of IEEE International conference on mobile adhoc and sensor systems, pp. 1-9, 2007

[23] Y. Xu, J. Heidemann, and D. Estrin, “ Geographyinformed energy conservation for Ad Hoc Routing", in proceedings of international conference on mobile computing and networking, 2001, pp. 70-84

[24] H. Luo, F. Ye, J. Cheng, S. Lu, and L. Zhang, 'TTDD 
Two-Tier Data Dissemination in large scale wireless sensor networks", Wireless Networks, vol. 11, no. 1-2, pp. 161175,2005

[25] A. G. Delavar, S. Shamsi, N. Mirkazemi, and J. Artin, “ SLGC: Anew cluster routing algorithm in wireless sensor networks for decrease energy consumption", International journal of computer science, engineering and application, vol. 2, no. 3, pp. 39-51, 2012
[26] S. Lindsey, C. Raghavendra, and K.M. Sivalingam, "Data Gathering Algorithm in sensor networks using energy matrices", IEEE Transactions on parallel and distributed systems, vol. 13, no. 9, pp. 924-935, 2002]

[27] S. Jung, Y. Han, and T. Chung, "The concentric clustering scheme for efficient energy consumption in the PEGASIS", in Proceedings of $9^{\text {th }}$ international conference on advanced communication technology, pp. 116-121, 2007 